\title{
Reflective thinking in clinical nursing education: a concept analysis
}

\author{
M Chabeli, D.Cur., Associate Professor, Department Of Nursing, Rand Afrikaans \\ University \\ M Muller, D.Cur., Professor, Department Of Nursing, Rand Afrikaans University
}

\section{Abstract}

Over decades nursing had an interest in clarifying and developing its knowledge base and its conceptual foundation. Reflective thinking has become a popular word in nursing education world wide, but its meaning and effective use remains debatable because of lack of clarity in its meaning (Mackintosh, 1998:553). The researcher engaged in the concept analysis of reflective thinking so as to fully understand its meaning and interpretation, hence the research question to be addressed by this article is: "What is the meaning of reflective thinking in clinical nursing education?"

This article seeks to explore and describe the conceptual meaning of reflective thinking in clinical nursing education using the method of concept analysis as outlined by Wilson (1963:23-39) and Gift (1997:75,76). Concept analysis of reflective thinking constitutes the first phase of a study to develop a model to facilitate reflective thinking in clinical nursing education, thus ensuring theoretical validity of the model.

An extensive examination of domain specific and various disciplines' literature was explored as part of the concept analysis. A selection of information regarding variations and similarities in the use and interpretation of reflective thinking across clinical nursing education was drawn from computerised data bases. This increased the rigor and the findings of the analysis. Through deductive reasoning and drawing of inferences, attributes were clustered in an attempt to identify the apparent essence of the concept.

Three categories and the related connotations emerged as follows:

- $\quad$ Antecedents (Cognitive and affective thinking skills)

- Process (The three phases of reflective thinking)

- Outcome (New insight and changed perspective).

Reflective thinking was considered from the result of concept analysis as a cyclic, interactive constructing mental process to improve practice in a specific context. It is recommended that a model to facilitate reflective thinking in clinical nursing education be developed based on the results of this concept analysis.

Key words: Reflective thinking, clinical nursing education, antecedents (cognitive and affective thinking skills), awareness and disequilibrium phase, interactive constructing process, consolidation phase, new insight and changed perspective as an outcome of reflective thinking.

\section{Introduction}

Reflective thinking has become a buzz-word in the educational arena nationally and internationally. It has become a thorny issue in clinical nursing education as an educational tool to improve clinical practice, especially in the event of outcome-based education, community-based education, problem-based learning and evidence-based practice.

The South African Education System is faced with key challenges with regard to provision of quality assurance in education, as well as the quantity and quality of graduates in line with the best practice internationally. Central to the outcomes-based education system, community-based education and problem-based learning, is learner-centred methods of teaching and evaluation that facilitate reflective thinking through interaction.

Nursing, as a practice-orientated profession should pay considerable attention to the development and clarification of its knowledge base in general and in clinical nursing education in particular. Confusion in facilitating clinical nursing education arises due to conceptual problems, yet concept clarification plays an important role in the intellectual development of knowledge, skills and values of everyday existence. 
Reflective thinking has become a popular word in nursing education world wide but its meaning and effective use remains debatable because of lack of clarity in its meaning (Mackintosh, 1998:553). The researcher engaged in the concept analysis of reflective thinking so as to fully understand its meaning and interpretation, hence the research question to be addressed by this article is: "What is the meaning of reflective thinking in clinical nursing education?"

The results of the concept analysis could provide a conceptual framework as a point of departure to guide the empirical phase of a study to develop a model to facilitate reflective thinking in clinical nursing education.

An overview of the method of concept analysis is described, followed by the description of the results in accordance with the identified categories and the related connotations of reflective thinking. A theoretical definition is formulated and theoretical validity is thus ensured.

\section{Method: concept analysis}

The method of content analysis as outlined by Wilson (1963:23-39) and Gift (1997:75,76) provided a framework to conduct a concept analysis of reflective thinking in clinical nursing education. Of the eleven steps described by Wilson (1963) in concept analysis, only seven steps appropriate to the study were used, based on the assumption that the concept under study should be "mature". This means that the concept should be clear and distinct, clearly defined and well differentiated from other concepts (epistemological principle), and that concepts should be applicable to the world and be appropriate to their use in the context (pragmatic and linguistic principle) Gift (1997:75,76). The method of concept analysis used is indicated in figure one.

Wilson (1963:23-39) suggests that the best way to conduct a good concept analysis is to follow all the steps in their order. The author contends that in some cases one or more steps may be omitted according to the sensitivity of the analysts, which will enable them to make good use of the appropriate steps of the strategy. The researcher made use of all the steps except the contrary, related, borderline and

\section{Figure 1: Method of concept analysis - selected steps (Wilson 1963)}

the invented cases. A brief overview of the method is described according to the selected steps, as applied to the concept of "reflective thinking" within the context of clinical nursing education.

\section{Isolating questions of concept}

Wilson (1963:23) states that before embarking on a concept analysis, the analyst should ensure that the question being answered is one that requires the meaning of the concept. The analyst should ask 'what counts' as the concept or 'what criteria' are being used to determine the meaning of the concept. The way in which questions of concepts are answered depends entirely on the angle from which the analyst is looking at them (Wilson, 1963:23).

Questions are often raised about the nature of reflective thinking in nursing education, nursing practice and nursing research. Should reflective thinking be used as an educational tool in nursing education? Should reflective practice be used to evidence efficient practice? Can reflective thinking be measured or evaluated in practice? These are some of the questions that raise the underlying anxiety in nursing. The study particularly isolated the concept of reflective thinking in order to answer the question: "what is the conceptual meaning and nature of reflective thinking within the context of clinical nursing education?"

\section{Finding the right answers}

The step of finding the right answers requires the analyst to determine which elements are essential to the 'core' of the concept and which are not. Wilson (1963:25) points out that there are no final right answers in a concept analysis, but emphasises that there are primary and central uses for the concept that can be distinguished through a thoughtful analysis.

From the analysis of the concept of reflective thinking, the essential attributes/connotations are identified. Wilson's method of concept analysis is an inductive, descriptive means of enquiry used to clarify the current status of the concept by identifying a consensus in the use and interpretation of the concept. A number of connotations for reflective thinking are identified from both primary and secondary sources such as dictionaries, thesauruses, books, articles, related conceptual and theoretical frameworks as well as data drawn from computerised databases. Through deductive analysis, synthesis and drawing inferences, attributes were clustered in an attempt to identify the apparent essence of the concept.

\section{Model case description}

To identify the attributes and their related connotations in order to apply reflective thinking meaningfully in clinical nursing education, a model case was identified and described as adapted from Benner et al (1999) using the attributes as indicated in table 2. According to Wilson (1963:28) model cases are the paradigm or exemplary cases of the concept under study. A model case of a concept enhances the degree of clarification offered as a result of analysis by 
providing an everyday example that includes the attributes of the concept (Rodgers, 1989:333).

\section{Social context}

Wilson (1963:33) states that language only occurs within a social and cultural context. Thus concepts take on meaning within that particular context. A sensitive analyst must take into account the social and cultural milieu in which the concept under study is used. Wilson suggests that the analyst might ask who might use the concept, when, why, how and so forth as a way of determining the context in which it is likely to be used.

Reflective thinking may provide different interpretations across cultures, regions and even disciplines. The clinical nursing education context in which reflective thinking of learners has to be facilitated, provided the researcher with insight into the essential nature of the concept. To understand the nature of reflective thinking and how it has to be facilitated, one must understand the complex nature of clinical nursing education as the context occurring within the legal, ethical and professional boundaries in the country.

\section{Underlying anxiety}

Closely associated with considering the social and cultural context of a concept is examining the underlying anxiety associated with it (Wilson, 1963:34). To determine the feelings, the tone and important insights about the concept, Wilson suggests that the analyst should ask questions such as: has the concept generated strong feelings or controversy? Is there a debate about the issue? Is it generally positive, or is it negative? These questions may provide the analyst with insight that may emerge concerning the concept under study. Reflective thinking has become a buzzword in the educational arena nationally and internationally. It has become a thorny issue in clinical nursing education as an educational tool to improve clinical practice, especially in the event of outcome-based education, community-based education, problem-based learning and evidence-based practice.

Concept analysis in this research will contribute to the underlying anxiety by clarifying the conceptual meaning of reflective thinking to be able to use it in developing a model to facilitate reflective thinking in clinical nursing education.

\section{Practical results}

Wilson (1963:34,35) argues that analysing a concept should have some practical results. It ought to make some difference in our lives. The authors are of the opinion that if the results of concept analysis are not useful, analysis was a waste of time - then something is seriously amiss with the language in which the question of the concept was expressed.

The results of the concept analysis of reflective thinking could be helpful in that the attributes could be used in the description of a theoretical definition of reflective thinking. The application in this research is as follows (refer to results): phases of the reflective thinking process are identified, influenced by the cognitive and affective thinking skills as antecedents in their level of complexity as follows: The first phase is the awareness and disequilibrium phase where acquisition of knowledge guided by the receptive attitude takes place. This knowledge has to be comprehended for positive response to take place. The second phase is characterised by an interactive constructing process in which learners should critically analyse information, taking into consideration the value system of the self and others, and synthesise the information creatively in an organised manner to make meaningful interpretation of the situation. The third phase is when the consolidated knowledge and experience are evaluated and internalised and used for rational clinical decision-making and problem solving. The outcome of reflective thinking is demonstrated by the development of new insight and a changed perspective in order to improve practice. Use of the accumulated knowledge and experience enables the learner to function independently and autonomously in practice, and to develop skills for lifelong learning. These phases with their related cognitive and affective thinking skills will help the facilitator to select appropriate teaching, assessment and evaluation methods that are learner-centred to facilitate reflective thinking in accordance with the learner's level of training.

\section{Results in language}

Wilson (1963:36-38) suggests that in defining a logical structure for a concept, one should choose the essential attributes of a concept that are most sensible and useful to make the definition meaningful so that the concept shall be used to the fullest advantage. For the concept of reflective thinking, the following are the most useful criteria applied in this research to describe the theoretical definition:

\section{A state of awareness and disequilibrium triggered} by the uncomfortable feelings and thoughts.

2. A cyclic, interactive constructing mental process influenced by cognitive and affective thinking skills in their hierarchical order as antecedents.

3. The use of the consolidated knowledge and experience.

4. Acquisition of new insight and a changed perspective to be used for rational decision making and solving of clinical problems as a subsequent outcome. A theoretical definition will be formulated after the results of concept analysis have been described.

\section{Description of results}

Three categories and the related connotations emerged:

- Antecedents (cognitive and affective thinking skills in their hierarchy as adapted from Blooms' taxonomy 1956)

- $\quad$ Process (three phases of reflective thinking process. Phase one: awareness and disequilibruim; phase two: interactive constructing process; phase three: consolidation for rational decision making and prob- 
CATEGORIFS ATTRIBUTES
REI ATEDCONNOTATIONS

\begin{tabular}{|c|c|c|}
\hline Antecedents & \begin{tabular}{ll}
\multicolumn{2}{l}{ Cognitive thinking skills } \\
- & Knowledge \\
- & Comprehension \\
- & Analysis \\
- & Synthesis \\
- & Evaluation
\end{tabular} & $\begin{array}{ll}\text { Affective thinking skills } \\
\text { - } & \text { Receptivity } \\
\text { - } & \text { Responding } \\
\text { - } & \text { Valuing } \\
\text { - } & \text { Organisation } \\
\text { - } & \text { Internalisation }\end{array}$ \\
\hline Process & $\begin{array}{l}\text { - } \quad \text { Phase 1: Awareness and disequilibrium } \\
\text { - } \quad \text { Phase 2: Interactive constructing process } \\
\text { - } \quad \text { Phase 3: Consolidation of knowledge and experience }\end{array}$ & \\
\hline Outcome & $\begin{array}{l}\text { New insight and changed perspective for rational decision } \\
\text { making and problem solving to improve practice }\end{array}$ & \\
\hline
\end{tabular}

lem solving).

- Outcome (new insight and changed perspective).

Reflective thinking is considered as a cyclic interactive constructing mental process to improve practice in a specific context.

The results of the concept analysis of reflective thinking demonstrate the antecedents influencing the reflective thinking process resulting in new insight and changed perspective as the outcome of reflective thinking displayed in figure two.

A brief description of antecedents (cognitive and affective thinking skills) followed by the process (phases of reflective thinking), and the outcome (new insight and changed perspective) to make rational decisions and solve problems in practice will be made in accordance with table two. Lastly, the theoretical definition of reflective thinking is formulated using the identified attributes.

\section{Antecedents: cognitive and affective thinking skill}

Walker and Avant (1988:43) define antecedents as necessary skills and events that must occur prior to the occurrence of the event or phenomenon, whilst Rodgers (1989:330) describe antecedents of a concept as events or phenomena that are generally found to precede an instance of the concept. Almost all the literature sources explored revealed that the primary antecedents, or situations preceding reflective thinking process are the cognitive and affective thinking skills as demonstrated in the writing of Beyer (1988:47-49) ... any act of thinking involves a com- bination of operations, knowledge and dispositions. The knowledge (cognition) is designed to produce meaning, while the disposition (affective) component supports skilful thinking, guides it, and, in effect, drives it. Components of thinking are closely interrelated.

The researcher found it appropriate to adapt the educational objectives in accordance with Bloom's taxonomy (1956). The cognitive thinking skills are, from the lowest to the highest: knowledge, comprehension, application, analysis, synthesis and evaluation. The affective thinking skills are as follows: receptivity, responding, valuing, organisation and internalisation. The adaptation of the cognitive thinking skills comes in where the researcher omits application as the third level of reasoning since the application of knowledge in this study occurs when the learner has internalised the professional values and demonstrate the ability to make rational decisions and solve problems. To avoid repetition, both the cognitive and affective thinking skills as antecedents influencing the process of reflective thinking will be described simultaneously in relation to the phases of reflective thinking.

\section{PROCESS: Phases of reflective thinking in relation to cognitive and affective thinking skills as antecedents}

The process of reflective thinking constitutes three identified phases of reflective thinking influenced by the cognitive and affective thinking skills in their hierarchical order. The schematic representation in figure one depicts the relationship between the phases of reflective thinking and the cognitive and affective thinking process as anteced- 
ents.

Phase one of the reflective thinking process is the awareness and disequilibrium phase influenced by (knowledge, receptivity, comprehension and responding) respectively in a specific situation. Phase two is the interactive constructing process that requires (critical analysis and synthesis of information as supported by values and the ability to organise information). Phase three is the consolidation phase where the accumulated knowledge and skills are evaluated and internalised, leading to new insight and a changed perspective as the outcome of reflective thinking, to enable learners to make rational clinical decisions and solve problems to improve practice.

Note that the phases are integrated, and the level of complexity increases with the phases as the learner's reflective thinking skills develops. Gravett (1996:10) argues that it is important to realise that the suggested phases will not necessarily feature in a single session. They may not necessarily be clearly distinguishable and successive. The logical order will be determined by the context in which reflective thinking occurs. Gravett (1996:10) maintains that the facilitator needs to pay attention to the fact that learners indeed receive the opportunity to confront their existing conceptions and the possible shortcomings or flaws in the conceptions. The phases are described according to their hierarchy from the lowest to the highest phase.

\section{Phase 1 - Awareness and disequilibrium}

Awareness, according to Benner et al. (1999:568), refers to skill of 'seeing' - a skill of recognition. Awareness in a person is triggered by insufficient knowledge and skills or any uncertainty in a given situation. Disequilibrium on the other hand refers to a disturbance in search for mental balance. Piaget (in Woolfolk, 1990:46) states that if the situation does not satisfy the learner and is queer, then disequilibruim exists and the learner becomes uncomfortable in thoughts and feelings. The two terms are related in that insufficient knowledge or uncertainty will disturb the mental balance of an individual. Self-reflective questions such as: What knowledge do I have in this situation? Who am I? What do I believe in' Given a chance, would I make any difference? If not, what will be the alternative? are usually asked (King $\&$ Kitchener, 1997:102). These questions motivate the learner to keep on searching for a solution and thus thinking changes and moves ahead.

According to Hunt (in Woolfolk, 1990:59), disequilibrium must be kept "just right" to ensure growth on the part of the learner by creating dissonance to stimulate thinking, for example, setting up situations that lead to errors can help create an appropriate level of disequilibrium. Learners must experience some conflict between what they think should happen and what actually happens. They may rethink their understanding and examine their reasoning, so that new knowledge may develop. In the same vein Scanlan \& Chernomas (1997:1179) and Burrows (1995:3460) main- tain that the state of discomfort may arise from surprise or a unique situation in which the individual's knowledge and feelings are insufficient to explain what is happening.

The facilitator is challenged by the responsibility to create an environment that will foster thinking through scenarios that cause dissonance and disequilibrium to encourage learners to engage in active construction of their own knowledge and skills in clinical nursing education. How knowledge, receptivity, comprehension and responding thinking skills as antecedents influence phase one of reflective thinking will be described.

According to Concise Oxford Dictionary (1995), knowledge is awareness or familiarity gained by experience, whereas Goodwin and Klausmeier (1975:242) assert that knowledge denotes factual information that is learned. Knowledge implies authority and reliability (Blackburn, 1999:47). Knowledge of the basic essentials such as facts, ideas, concepts, principles, guidelines, generalisations, methods and theories of a discipline form the building blocks on which reflective thinking is based. Dewey (1933:104) aptly states that no reflective thinking can occur in a vacuum. Scanlan and Chernomas (1997:1139) argue that it would be more useful to think of conceptualisation as the first stage of reflective thinking that one would encounter in practice, since acquisition of knowledge in a specific context causes one to have a genuine interest in constructing new knowledge. It is from this knowledge framework that learners can construct knowledge by interpreting perceptions on the basis of prior knowledge and existing beliefs to reach new perspectives (Tynjala, 1997:288).

Boud et al. (in Wong et al. 1995:50) are of the opinion that reflective thinkers will always return to the previous knowledge and experience, recollect what has taken place, attend to feelings, and relate new data to that which is already known. They will seek relationships between data, determine the authenticity of ideas and feelings that resulted and then make the resultant knowledge and feelings their own. Therefore previous knowledge and concepts are an instrument of understanding and explaining things that are still uncertain and perplexing.

Basic knowledge is important, especially to the novice since, according to Benner (1982:403), novice students have no experience of the clinical situation. Hence, they have to be taught about the situation in terms of 'objective attributes' that are features of the task that can be recognised without situational experience. Learners in phase one are taught basic concepts, rules, principles, methods and theories to guide their action. Objective attributes (weight, temperatures, blood pressure) are taught better through lecture demonstrations, observation and narratives.

Learners must be encouraged to identify, define and describe clinical events. Benner et al. (1999:47) assert that acquiring an embodied skill involves learning through the body, through all the senses. It entails learning new embodied habits of attentiveness, thinking and acting. The knowledge gained will then form what Ausubel (1968:57) 
refers to as 'cognitive structures" to link future experiences in order to provide a meaningful reality. Ausubel refers to the cognitive structure of an individual as the stability, clarity and organisation of knowledge in a given discipline that the individual already commands.

However, Ausubel (1968:116) gives a warning that, for one to be able to interpret situations meaningfully, the following aspects have to be considered: a) the nature and availability of relevant anchoring ideas in the cognitive structure; b) the stability and clarity of these ideas and c) the discriminability of the learning material from its anchoring ideas to motivate the learner. These aspects may have a positive impact on one's readiness for reflective thinking process to occur. Successful knowledge acquisition is influenced by the individual's state of receptivity.

Receptivity refers to the ability or readiness to receive impressions or ideas. It is concerned with receiving stimuli (Concise Oxford Dictionary, 1995). According to Ennis and Krathwohl (in Beyer, 1988:49), positive attitudes and dispositions are significant to the inquiring mind, examining a variety of view points, using credible sources, seeking and giving reasons and evidence in support of a claim. Wong et al. (1995:57) and Boud et al (in Gray \& Pratt 1991:361) assert that to remove uncomfortable feelings in order to acquire knowledge, one has to utilise positive feelings and remove obstructive feelings. Positive feelings need to be identified, explored and enjoyed. This allows the learner to consider events rationally and with good feelings. Therefore, the feelings in question need to be discharged or transformed in a way that enables us to regain our flexibility and creativity in responding to the current situation. This can be made possible through an individual's self-awareness.

Self-awareness makes one consider one's thoughts, feelings, attitudes and beliefs and the extent to which you acknowledge prior experience as significant, creating the potential for each moment to be meaningful (Belensky et al. in John \& Freshwaters, 1998:55). It is a building block for personality integration, one's private view of one's self, one's weakness, strength and personality (Goodwin \& Klausemeier, 1975:306).

Dewey (1933:30,31) argues that self-awareness will be demonstrated by the possession of attitudes such as: openmindedness, whole-heartedness and responsibility. Openmindedness, according to Dewey (1933:30), includes an active desire and willingness to listen to more sides than one, to heed to the facts from whatever source they come, and to give full attention to alternative possibilities. Palmer et al's (1994:49) opinions are that open-mindedness is a state in which things are not taken for granted, but selfquestioning and self-awareness is promoted. Ross and Hannay (1986:13), Baron (1988:392) and Boyd and Fales (1983:108) regard open-mindedness as a virtue of reflective thinking.

Dewey (1933:31) refers to whole-heartedness as genuine interest involving the analysis of feelings and emotions. It demands interest and an inner strength for genuine reflec- tion on the entire experience. Responsibility, according to Dewey (1933:32), is an attitude that is necessary to win adequate support for new points of view, new ideas and enthusiasm. A responsible person will respect the ideas, beliefs, emotions and desire of others. The person will demonstrate courage, trust, empathy, enthusiasm and commitment to the existing situation (Boyd \& Fales, 1983:110; Wilson \& Jan, 1993:8 and King, in Brooks \& Thomas, 1997:52). The supporting attitudes facilitate the comprehension of the learner. It is thus important for the facilitator to establish the learner's prior knowledge and receptivity, forming a strong background in facilitating comprehension and a positive response to clinical nursing education.

Comprehension refers to the ability to achieve a mental grasp of the nature, significance, or explanation of something and to have a clear or complete idea of it (Harlock, 1978:354). However, Beyer (1988:59) postulates that the learner's comprehension is demonstrated by the ability to combine translation (paraphrasing a communication while maintaining the intent of the original); interpretation (summarising or explaining information in own words), and extrapolation (when information is projected beyond the given data).

As pointed out by Dewey (1933:133) "Without comprehension of ideas and meanings, facts would heap-up like grains of sand, they would not be organised into intellectual unity". In search of how comprehension should be achieved, Burrows (1995:348) contends that the ability to reflect on the past assists reasoning and comprehension. Ausubel's (1968:540) opinion is that language also increases comprehension in that the representational properties of the words facilitate the transformational aspects of thought. Language adds meaning. It is a tool through which classifying, clarifying, translation, interpretation and extrapolation to construct meaning can be done. Dewey (1933:232) argues that through language, concept learning is facilitated, and collaborative meaning-making through discourse is enhanced. Language becomes a resource on which imaginative combinations and variations may be built. Hence Dewey (1933:232) maintains that thinking is impossible without language. Vygotsky (1986) on thought and language reiterates this assertion.

Culture facilitates comprehension because it provides the basis for language formation. Knowledge, ideas, attitudes and values are shaped mainly through our interaction with others within a specific cultural context, with language being the mediating factor (Vygotsky, 1978). Through culture the reasoning of learners is empowered (Ausubel, 1968:540). It is clear that the facilitator should consider language clarity and culture as interactive facilitating tools of reflective thinking when creating an environment conducive to learning through discourse in clinical nursing education.

Reasoning remains the hallmark in the facilitation of reflective thinking. Mulligan and Graffin (1992:181) assert that reasoning determines how we interpret, analyse, synthesise and evaluate the real world. According to Russow and Curd (1989:1), reasoning is about justification and evidence 


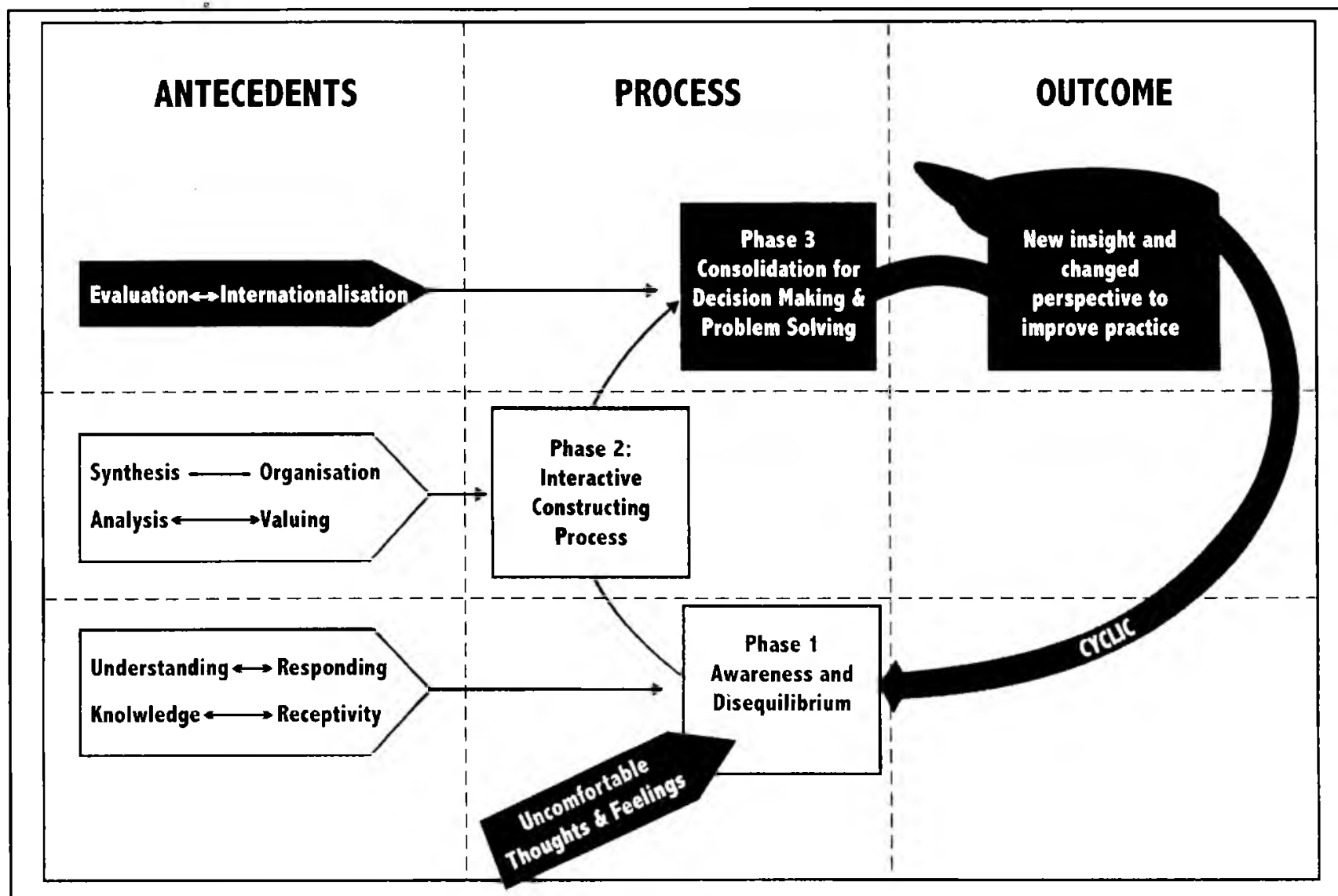

Figure 1: Phases of reflective thinking in relation to cognitive and affective thinking skills as antecedents

to justify claim to 'truth'. Clinical reasoning such as deducion, induction, retroduction, generalisation and reasoning by analogy should be introduced early in clinical nursing education (Jones, in Gray \& Pratt, 1991:56-58). Strategies such as brainstorming, field trips and simulations in the form of role-play, video games and introducing simple unstructured problems would be helpful in facilitating comprehension (King \& Kitchener, 1994:75,228). Comprehension, according to Harlock (1978:356), has an affective quality to enable the individual to respond meaningfully to the situation.

Responding is defined as the ability to show answers in words and feelings (The Pocket Oxford of Current English 1961). The kind of response depends on the willingness to share and to listen to others, motivation and enthusiasm on the part of the learner. Willingness, according to Harlock (1978:356), refers to the "emotional weighting", which means how an individual feels about the situation. Inappropriate response indicates that no grasp of the meaning has occurred. It is important to realise that the first phase of reflective thinking forms the basis for the second phase of reflective thinking that is focused on the interactive constructing process.

\section{Phase 2: Interactive constructing process}

The word interactive refers to mutual, reciprocally active, correlative, interchange, exchange and interdependent
Roget (1991:54), whilst Pietrofesa et al. (1978:4,6) define interactive as a mutual relationship of individuals seeking help..., always facilitative and fostering growth..., it is a mutual enterprise and is based on respect for the individual..., specific skills such as empathy, attending, listening, responding and self-awareness are used. Constructing refers to making by fitting parts together, building, form by interpretation or explanation whilst the word process refers to a course of action (Concise Oxford Dictionary, 1995).

As already indicated, the interactive constructing process of reflective thinking is influenced by higher order cognitive and affective thinking skills, such as analysis, synthesis and their corresponding dispositions namely, values and organisation skills. Analysis refers to the act or process of breaking down something into its constituent parts for the purpose of detailed examination of the elements of a substance (Dewey 1933:127). The process of analysis requires active participation of the learner in the construction of own clinical knowledge, skills, attitudes and values through collaborative discourse and the sharing of ideas and thoughts (Wells, 2000:6; Clarke et al, 1996:176). Learners get the chance to think about how the experience relates to and/or expands previous knowledge. Unless there is critical analysis that reviews and links the experience to either the past or the future, reflective thinking has not occurred (Scanlan \& Chernomas, 1997:1139,1140).

A good clinician always interprets the present situation in 
soning in a given situation (Benner et al. 1999:10). Questions such as: "What is happening? What is the nature of...? What is the experience of...? How might this be different...?" will stimulate the interactive constructing process. Providing answers to these questions will involve the learner in active participation to construct this knowledge. The questions demand reasoning and justification of ideas, thoughts and feelings (John \& Freshwaters, 1998:139,55). Facilitators can focus on problems that need the learner's ability to reason deductively and inductively in identifying underlying assumptions in an argument through logical reasoning - use less structured problems and more ill-structured problems that create dissonance (King \& Kitchener, 1997:78).

Reasoning involves justification of ideas, thoughts and feelings based on evidence. Ennis and Norris (in King \& Kitchener, 1997:79) are of the opinion that a measure of the quality of reflective thinking will need to attend to the nature of the justification of the judgement as well as to the judgement itself in a specific situation. It is important for learners to seek more justification whenever anything seems unclear. Ways to develop the reasoning skills are classifying, clarifying, interpreting, justification of ideas and thoughts, and to engage learners in strategies such as reflective journal writing, nursing process, case studies, peer tutoring and concept mapping (Gravett, 1996:15,16; Varcoe, 1996:120-125; Riley-Doucet \& Wilson, 1997:965-966).

Higher order thinking such as analysis needs support and guidance by dispositions such as empathy, mutual trust and respect, confidence, courage, commitment, willingness, open-mindedness, genuine interest, enthusiasm, empathy, justice, responsibility and accountability (Beyer, 1988:49; Bakan in Clarke et al, 1996:179). Bennette (1995:138) asserts that empathy is manifested in feelings, thoughts or behaviour. It has an important affective influence on reflective thinking since it enhances the understanding of different cultural values and beliefs. Empathy involves respect and mutual relationship, good listening and communication skills, patience, good rapport, a climate of support, openness, non-judgemental attitudes and willingness, which value individuals as unique persons in their own right (John \& Freshwaters, 1998:46; Mc Gill \& Beaty, 1995:157-161).

Mutual trust and respect play an integral part during the process of analysis. Pamela and Loriz (1998:20) believe that the interactive constructing process of reflective thinking must occur in an atmosphere of mutual trust and respect. Trust enables the learner to be open to different perspectives so that compromise can occur by accommodating divergent positions through mutual concessions. Trust, according to McGill and Beaty (1995:37), builds confidence and courage to explore the thoughts and feelings of others truly and freely.

Reflective thinking needs courage, a risk taker and good assertive skills to express one's thoughts, to provide justification based on evidence so as to establish meaning. Courage leads to commitment and helps individuals direct their thinking and behaviour (Bodrova \& Leong, 1996:11; Nelson-Jones, 1989:11). Commitment sustains and enhances the reflective thinking process. It underpins the interactive constructing process in that the learners begin to acknowledge and appreciate the relative merits of choice in making their own clinical decisions (Burrows, 1995:348). Boud et al. (in Wong et al, 1995:49) state that commitment to interaction becomes the life force of the learner in the interactive constructing process of reflective thinking. The information that has been explored through analysis supported by values as indicated must be pooled together and harmonised to provide new insight through the process of synthesis and organisation.

Synthesis refers to the process of building up elements and ideas into a connected whole (Concise Oxford Dictionary, 1995). Synthesis and organisation are the pillar components of the interactive constructing process responsible for integrating and constructing new knowledge in relation to the existing conception and experiences (Atkins \& Murphy, 1993:1190). The process of synthesis requires the use of creativity and imagination to develop new insight and changed perspectives. Creativity is a process by which something new, either an idea or an object in a new form of arrangement is produced. What is created is always new, unique and goal-directed. It involves a combination of old ideas into new forms that are different and original, but the old form the basis of the new, argued (Harlock, 1978:324).

A creative learner will use analogies, metaphors, models and inferences, and generate hypotheses within any specific discourse to express understanding and meaning (Bruni in Klopper, 1994:21). This permits an 'Aha' sense of feeling and a richer flow of ideas, thus opening up the way to solutions of problems, especially complex ethical and moral problems in clinical practice. Learners could be engaged in teaching strategies such as group projects, seminars and workshops and assessment and evaluation methods such as portfolio assessment and reflective tutorials to facilitate reflective thinking.

The success of the learner's ability to synthesise depends on the learner's organisational ability. Organisation refers to maintaining internal order through the inherent tendency to systematise and integrate intellectual structures into coherent order (Bybee \& Sund, 1982). Organisation plays an integral part in reflective thinking since construction of meaning is done through organised reasoning of thought processes, feelings and experiences. Putting ideas and feelings together creatively in perspective to bring up new insight is what Bybee and Sund (1982:194) refer to as "cognitive organisation to fit the new experience" which is an important component of reflective thinking. Dewey (1933: 47,49 ) refers to this mental activity as 'intellectual organisation'.

Developing organisation thinking skills requires one to be systematic, consistent and flexible, and to have perseverance (Dewey, 1933:30; Burrows, 1995:347). The use of existing theoretical frameworks can be helpful in organising information such as the nursing process or Maslow's hierarchy of needs approach. Dewey (1933:126) warns that synthesised and organised information needs to be evaluated for acceptance or rejection, based on justified evidence. 
This leads the discussion to the third phase of reflective thinking.

\section{Phase 3: Consolidation phase for rational decision making and problem solving}

Consolidation phase aims at assisting learners to integrate and synthesise the knowledge they have constructed. Gravett (1996:13) contends that during the consolidation phase the connection between concepts and principles should be focused sharply. Consolidation phase is influenced by the highest cognitive and affective thinking skills. It is the phase where reflective thinking is demonstrated, since the learner is able to consolidate all the knowledge and experience gained throughout the course. This knowledge is evaluated for its worth, accuracy, relevance and acceptability in clinical nursing education. Evaluation involves the use of criteria and standards in a given situation (Beyer, 1988:173). Evaluation skills require the learner to be able to test the generated hypothesis and to make adequate assessment of the situation in clinical nursing education. Learners must come to a conclusion of what is right or wrong in a situation (Dewey, 1933:126). It is through evaluation that the learner will determine whether the prevailing information is to be internalised as professional values to improve practice or not.

Internalisation refers to making the acquired knowledge one's own by learning or unconscious assimilation (Concise Oxford Dictionary, 1995). It refers to the state where one adapts to the value system of the profession. It directs the way of life automatically (Van Hoozer et al. 1987:220). Internalisation represents the stage where reflective thinking actually takes place. Learners demonstrate the ability to make rational clinical decisions and solve problems based on previous conception and experience.

Schafer (1968:11) argues that the result of internalisation is operating with relative autonomy in decision making and problem solving. Botes $(2000: 28)$ is of the opinion that decisions made in a rational manner must, in some way or other, be justified. Considering the aspect of decision making in the clinical learning context, Pamela and Loriz (1998:17) suggest that the primary principle of justice and autonomy to make ethical decisions should be considered.

According to the principle of justice, a person should be treated according to what is fair, given what is due or owed. Efficient decision making and problem solving based on the principle of justice enables the learner to practise at a proficient and expert level. At this level, the learner Benner (1982:405) has a holistic deep understanding of the situation to improve clinical decision making. Benner (1982:405) states that, because of the internalised professional knowledge, skills and values, clinical decision making is now 'less laboured' since the learner is able to recognise the most important salient aspects needed for the situation at hand. Pamela and Loriz (1998:18) advocate the re-evaluation of performance in clinical nursing education. To reflect on the performance by asking reflective questions such as: "In retrospect, did I choose the best course of action? Would an alternative solution have been better and why? What went right and what went wrong and why?" Pamela and Loriz (1998:18) assert that these questions will force the learner to do self-assessment and self-evaluation, and subsequently go back to the reflective thinking cycle.

Based on the principle of autonomy, people have the right to determine their own actions based on their values and beliefs. Autonomous decisions make use of adequate information, are free of coercion, and are reasoned carefully, considering respect for human dignity and uniqueness of each individual (Pamela \& Loritz, 1998:17).

In clinical nursing education, learners at this level are expected to make astute ethical and moral decisions about a patient's life. The facilitator should promote the autonomy of learners by exposing them to various learning opportunities such as: taking charge of the unit under the guidance of the professional nurse in the nearby unit. Teaching strategies such as values clarification, clinical conference, self directed learning contracts and the research/community outreach projects that demand the learner to consolidate all the knowledge and experience gained during training should be used (Quinn, 1988:401). The learner is assisted to assume a sense of responsibility and accountability with confidence. At this level, learners are able to conceptualise reality and to contrast their own comprehensive frameworks, which enables them to justify and defend the decision they have taken (Gray \& Pratt, 1991:128). The frameworks emanating from their reflective thinking enhance the learners' feeling of product ownership and greater commitment to implementation.

\section{Outcome}

The outcome or consequences follow an occurrence of the concept (Rodgers, 1989:134). Consolidation phase and the outcome of reflective thinking are closely related since the acquired new insight and changed perspective of the learner in a given situation enable the learner to view clinical situations holistically in a comprehensive manner. The learner can demonstrate conceptual change, that is, transforming existing concepts (West \& Pine, 1985:2). Dewey (1933:77) asserts that a genuinely reflective activity terminates in declaring just what the outcome is.

The learner is expected to practise independently and autonomously. The facilitator should create opportunities for self-directed and self-regulating learning activities that will encourage collaborative, co-operative and shared discourse with other inter-disciplinary members of the health-related team (Schapiro \& Livingston, 2000:23-35; Mellish et al. 1998:75; Quinn, 1988:401; Ewan \& White 1984:119).

Knowledge constructed in this interactive mode is valuable and should improve practice and equip learners with lifelong learning skills. Reflective thinking is never-ending due to the dynamic complex challenges in clinical nursing education. The facilitator needs to keep exploring new learner-centred, learner-friendly methods of teaching, as- 
sessment and evaluation methods that will make the facilitation of reflective thinking of learners a reality. Having described the results of the concept analysis of reflective thinking to give a broader perspective of how the concept could be used in clinical nursing education, a theoretical definition, based on the identified attributes and connotations will be described.

\section{A theoretical definition of reflective thinking in clinical nursing education}

From the concept analysis, the following attributes and connotations form the basis of the definition of reflective thinking in clinical nursing education. Three main categories were identified as the antecedents, process and outcome. The related connotations of antecedents are cognitive and affective thinking skills in their hierarchical order as adapted from Bloom's taxonomy (1956). The process occurs in three phases influenced by the cognitive and affective thinking skills at different levels of complexity. The initial phase is the awareness and disequilibrium triggered by the uncomfortable thoughts and feelings. The second phase is the interactive constructing process, and lastly the consolidation phase where learners consolidate and integrate the acquired knowledge and skills to make rational clinical decisions and solve problems. The outcome of reflective thinking is new insight and changed perspective to improve practice. Reflective thinking is considered as a rational, progressive and cyclic mental process in nature.

These characteristics form the boundaries within which reflective thinking is defined as the concluding statement: "Reflective thinking is a rational, progressive, cyclic interactive mental process influenced by hierarchical cognitive and affective thinking skills. It is triggered by the uncertainty in a specific situation bringing about a state of mental awareness and disequilibrium which leads to an interactive constructing process followed by consolidation of knowledge that creates new insight and a changed perspective for clinical decision making and problem solving".

\section{Conclusion and}

\section{recommendations}

A theoretical definition on reflective thinking, within the context of clinical nursing education was formulated, based on the method of concept analysis. Challenges in clinical nursing education demand the use of reflective thinking in order to attain quality assurance in nursing education to improve practice and to restore and maintain the credibility of the profession in the eyes of the consumers of health care. It will force learners to remain lifelong learners and to practice responsibly with accountability. Learners will practice independently and autonomously, will gain a meaningful experience through the process of deconstruction, construction and reconstruction of meaning (Rossouw et al. 1994:70).

It is recommended that an empirical concept analysis of reflective thinking be conducted. It is also recommended that a model to facilitate reflective thinking in clinical nursing education be developed based on these results of concept analysis.

\section{References}

ATKINS, S \& MURPHY, K 1993: Reflections: a review of the literature. Journal of Advanced Nursing (18) 1188-1192.

AUSUBEL, DP 1968: Educational Psychology. A Cognitive View. London: Holt, Rinehart and Winston, Inc.

BENNER, P 1982: From Novice to Expert. American Journal of Nursing March 1982: 402-407

BENNER, P; HOOPER-KYRIAKIDIS,P \& STANNARD, $D$ 1999: Clinical wisdom and interventions in critical care. Philadelphia: W.B. Saunders Company.

BENNETTE, JA 1995: "Methodological notes on Empathy". Further consideration. Advanced Nursing Science 18(1) $36-50$.

BEYER, BK 1988: Developing a thinking skills programme. London: Allyn \& Bacon Inc.

BLACKBURN, S 1999: Thinking: A compelling introduction to philosophy. Oxford University Press.

BLOOMS, BS ed 1956: Taxonomy of educational objectives. The classification of educational goals. New York: McKay.

BODROVA, E \& LEONG, DL 1996: Tools of the mind. The Vygotskian approach to early childhood education. New Jersey: Prentice Hall, Inc.

BOTES, AC 2000: Critical thinkers by nurses on ethical issues like the termination of pregnancies. Curationis. September 2000: 26-31.

BOYD, EM \& FALES, AW 1983: Reflective Learning: key to learning experience. Journal of Humanistic Psvchologv 23(2): 99-117.

BROOKS, EM. \& THOMAS, S. 1997: The perceptions and judgement of senior baccalaureate student nurses in clinical decision making. Advance Nursing Science 19(3): 50-69 Aspen Publisher INC.

BURROWS, DE 1995: The nurse teacher's role in the promotion of reflective practice. Nurse Education Today (15): $346-350$.

BYBEE, RW \& SUND, RB 1982: Piaget for Education. London: Charles E. Merrill Publishing Company. A Bell and Howell Company.

CLARKE, B; JAMES, C \& KELLY,J 1996: Reflective practice: reviewing the issue and refocusing the debate. Inter- 
national Journal of Nursing Studies 33(2): 171-180.

\section{CONCISE OXFORD DICTIONARY 1995.}

DEWEY, J 1933: How we think. A restatement of the relation of reflective thinking to the educative process. Lexington: Massachusetts.

EWAN, C \& WHITE, R 1984: Teaching nursing: A selfinstructional handbook. London: Croom Helm.

GIFT, AG 1997: Clarifying concepts in nursing research. Pensilvania: Springer Publishing Company.

GOODWIN, WI \& KLAUSEMEIER, HT 1975: Facilitating student learning: An Introduction to Educational Psychology. New York: Harper and Row Publishers.

GRAVETT, S 1996: Instructions to promote effective learning. Bureau for Universitv Internal Publication. BUE (35): Rand Afrikaans University.

GRAY, G \& PRATT, R 1991: Towards a discipline of nursing. New York: Churchill Livingston.

HARLOCK, EB 1978: Child Development. Sydney: McGraw Hill International Editions.

JOHN, C \& FRESHWATERS, D 1998: Transforming nursing through reflective practice. London: Blackwell Science.

KING, PM \& KITCHENER, KS 1997: Developing refleclive judgement: Understanding and promoting intellectual growth and critical thinking in adolescent and adults. San Francisco: Jossey-Bass Publishers.

KLOPPER, HC 1994: The learning accompanist in nursing science. Monograph 2:36. Johannesburg: Rand Afrikaans University.

MACKINTOSH, C 1998: Reflection: A flawed strategy for the nursing profession. Nursing Education Todav 18: 553557.

Mc Gill, I \& BEATY, L 1995: Action Learning. A guide for professional management and education development. London: Kogan Page.

MELLISH, JM; BRINK, HIL \& PATON, F 1998: Teaching and learning the practice of nursing. Johannesburg: Heinemann.

MULLIGAN, J \& GRIFFIN, C 1992: Empowerment through experiential learning. Explorations of good practice. London: Kogan Page.

NELSON-JONES, R 1989: Effective thinking skills. Preventing and managing personal problems. London: Cassell Educational Limited.

PALMER, AM; BURNS, S \& BULMAN. C 1994: Reflec- tive practice in nursing. The growth of the professional practitioner. London: Blackwell Scientific Publications.

PAMELA, SC \& I ORIZ, L 1998: Decision making in practice. A practical model for resolving the type of ethical dilemmas you face daily. American Journal of Nursing. June 1998. 98(6):17-20.

PIETROFESSA, JJ; HOFFMAN, A; SPLETE, HH \& PINTO, DV 1978: Counselling: Theory, research and practice. Chicago: Rand McNALLY.

QUINN, FM 1988: The principle and practice of nurse education. London: Croon Helm.

RILEY-DOUCET, C \& WILSON, S 1997: A three-step method of self-reflection using reflective journal writing. Journal of Advanced Nursing. 25:964-968.

RODGERS, BL 1989: Concept, analysis and the development of nursing knowledge: the evolutionary cycle. Journal of Advanced Nursing. 14: 330-335.

ROGET, P 1991: Roget's Thesaurus of English words and phrase. London: Dent.

ROSS, EW \& HANNAY, LM 1986: Towards a critical theory of reflective inquiry. Journal of Teacher Education. JulyAugust 1986: 9-15.

ROSSOUW, GJ; LOTTER, HPP; SERFONTEIN, P; SNYMAN, J \& VAN VEUREN, PJJ 1994: Skilful Thinking. An introduction to philosophical skills. Pretoria: HSRC Publisher.

RUSSOW, LM \& CURD, M 1989: Principles of reasoning. New York: St Martin Press.

SCANLAN, JM \& CHERNOMAS, WM 1997: Developing the reflective teacher. Journal of Advanced Nursing. 25:1138-1143.

SCHAFER, F 1968: Aspects of Internalisation. New York: International University Press.

SCHAPIRO, SR \& LIVINGSTON, JA 2000: Dynamic selfregulation: The driving force behind academic achievement. Innovative Higher Education. 25 (1): 23-35.

\section{THE POCKET OXFORD DICTIONARY OF CURRENT ENGLISH 1961.}

TYNJALA, P 1997: Developing education student's perceptions of the learning process in different learning environment. Learning and Instruction 7 (3): 277-292.

VAN HOOZER, HL; BRATTON, BD; OSTMOE, PM; WEINHOLTZ, D; CRAFT, MJ; GJERDE, CL \& ALBANESE, MA 1987: The teaching process. Theory and practice in nursing. Norwalk: Appleton-Century-Crofts. 
VARCOE, C 1996: Disparagement of the nursing process: the new dogma? Journal of Advanced Nursing 23:120-125.

VYGOTSKY, LS 1986: Thought and Language. Cambridge, MA: Harvard University Press.

VYGOTSKY, LS 1978: Mind in Society. The development of higher psychological processes. Cambridge, MA: Harvard University Press.

WALKER, LD \& AVANT, KC 1988: Strategies for Theory Construction in Nursing. Norwalk: Appleton and Lange.

WELLS, G 2000: Dialogic inquiry in education: Building on the legacy of Vygotsky. http://www.oisc.utoronto.ca/ حgwells/NCTE. Html.

WEST, L \& PINE, AI 1985: Cognitive structures and conceptual change. Florida: Academic Press.

WILSON, J 1963: Thinking with concepts. Cambridge: Cambridge University Press.

WILSON, J \& JAN, LW 1993: Thinking for themselves. USA: Heinemann. Portmouth, NH.

WONG, FKY; KEMBER, D; CHUNG, LYF \& YAN,L 1995: Assessing the level of student reflection from reflective journals. Journal of Advanced Nursing 22:48-57.

WOOLFOLK, AE 1990: Educational Psychology. New Jersey: Prentice-Hall. 